\title{
FORMAÇÃO DE ESPECTADORES TEATRAIS: UM EXPERIMENTO NA ESCOLA
}

\author{
Alexandre Gandolfi Neto
}


Este artigo apresenta um relato do resultado de uma prática pedagógica de ensino do teatro, com ênfase na recepção de espetáculos no contexto escolar, desenvolvida em decorrência de pesquisa acadêmica no Mestrado Profissional em Artes. A aplicação da pesquisa aconteceu em 2015, com alunos de ensino médio do Instituto Estadual de Educação, na cidade de Florianópolis, Santa Catarina. O experimento consistiu na recepção de 1 (um) espetáculo teatral com alunos espectadores da instituição, sendo que com um grupo de alunos foram desenvolvidos procedimentos extra espetaculares para formação de espectadores, enquanto os demais grupos somente tiveram proporcionada a fruição do espetáculo teatral. A pesquisa buscou trazer alternativas de abordagem da recepção teatral na escola para fomentar a formação de espectadores teatrais. A proposta pedagógica buscou relacionar dois tipos de experimentos: Formação de Espectadores e Formação de Público, de forma a verificar se os procedimentos extraespetaculares adotados no experimento de formação de espectadores contribuem para apurar a recepção dos alunos espectadores sobre os espetáculos, fomentando o prazer pela experiência estética.

Palavras-Chave: Formação de espectadores. Teatro-educação. Pedagogia do espectador.

\section{Em Busca do(A) Espectador(A)}

$\mathrm{N}$

o decorrer de quase duas décadas de vida dedicadas à Arte como professor, artista e produtor - pude verificar o foco no espectador e na espectadora como uma prática presente em todos os projetos que desenvolvi e que ainda desenvolvo dentro das instituições em que atuei e atuo. Como professor de teatro sempre tive o interesse em propor atividades pedagógicas, com o intuito de proporcionar o acesso dos e das estudantes ao teatro, o que se tornou uma prática constante na condução do meu trabalho. Estas histórias foram resgatadas e registradas na dissertação resultante da pesquisa que desenvolvi no mestrado Profartes, em 2016, quando me propus a refletir sobre a importância de proporcionar a recepção de espetáculos teatrais para alunos e alunas na escola como forma integrante do ensino teatral.

Nesse sentido, mobilizei a trajetória da pesquisa no caminho de aprofundar algumas questões, com o intuito de aprimorar o trabalho que desenvolvo na área da Pedagogia Teatral como: será que somente oportunizar o ato de assistir teatro na escola pode ajudar a formar espectadores para essa arte? Existem procedimentos que possam ser aplicados com o intuito de aprofundar a recepção do espectador? Que procedimentos poderiam ser utilizados para aprimorar a leitura do espectador para o espetáculo teatral?

Como pesquisador do Mestrado Profissional em Artes, me debrucei sobre informações teóricas sobre o assunto para construir o Projeto de For- 
mação de Espectadores Teatrais na Escola e desenvolvê-lo na instituição na qual me encontrava vinculado naquele momento. $\mathrm{O}$ objetivo foi verificar possibilidades de ampliar meu repertório de procedimentos para recepção teatral de forma a aprofundar e qualificar minha prática pedagógica, visando contribuir para as áreas que atuo: a educação e a arte.

Apresenta-se neste artigo o relato do desenvolvimento de uma proposta pedagógica para alunos de ensino médio de uma instituição pública - Instituto Estadual de Educação de Florianópolis, Santa Catarina -, com o objetivo de fomentar a formação de espectadores, estimulando o interesse pelo teatro através de procedimentos pedagógicos de aproximação à linguagem teatral.

A proposta pedagógica aqui descrita buscou relacionar dois tipos de experimentos: Formação de Espectadores e Formação de Público. Isto feito para verificar se os procedimentos extraespetaculares adotados no experimento de formação de espectadores contribuem para apurar a recepção dos alunos espectadores sobre os espetáculos, fomentando o prazer pela experiência estética.

Neste texto farei um breve relato do caminho percorrido e do resultado da pesquisa, sendo que uma abordagem mais aprofundada e detalhada pode ser encontrada no texto dissertativo. Primeiramente, é exposto um levantamento teórico do campo de estudos que deu suporte para a criação da proposta pedagógica onde são apresentados os objetivos e a importância da recepção teatral no ensino da arte na escola. No momento posterior é apresentado o campo de estudos, denominado Pedagogia do Espectador, descrevendo as peculiaridades e diferenças existentes entre propostas de Formação de Público em relação às de Formação de Espectadores. Como finalização descreve-se a proposta pedagógica e algumas conclusões obtidas através da análise do experimento.

\section{A Importância da Recepção no Ensino da Arte}
A
tualmente abordar a importância da recepção no processo de ensino-aprendizagem em arte pode parecer algo ultrapassado ou redundante, porém, é preciso esclarecer que os estudos e pesquisas nesta área ainda estão em pleno processo de investigação e reflexão, principalmente no teatro. O ensino do teatro com foco na área da recepção, ou seja, na formação do aluno e da aluna como espectador ou espectadora teatral, não é uma constante da atividade pedagógica, como recorda Beatriz Ângela Cabral em escritos datados de 1994, onde apresenta um panorama histórico sobre o ensino do teatro na escola: 
Historicamente o Teatro Educação desenvolveu-se sem platéia. Tudo o que se aproximasse deste conceito era disfarçado sobre outra terminologia ou vestido com objetivos educacionais tais como 'compartilhar,' 'trocar', etc. Entre as razões para esta postura estão a ênfase posta pela educação na 'experiência', e a suposição de que o 'mostrar' para uma platéia iria interromper uma experiência e o envolvimento com o trabalho. Apenas recentemente o papel da platéia está sendo reconsiderado na área, assim como seu potencial na aprendizagem (CABRAL apud ROSSETO, 2008, p. 18).

Abordar o fazer e o apreciar vem sendo cada vez mais entendido como abordagem complementar no ensino do teatro na escola. No âmbito local do município de Florianópolis é possível verificar uma participação crescente das instituições de educação, levando os alunos e as alunas para assistirem espetáculos cênicos nos equipamentos culturais da cidade.

Obviamente podemos listar uma diversidade de fatores que contribuíram para isto, como uma maior demanda de atividades culturais ofertadas de forma gratuita ao público, bem como a disponibilidade de transporte pela prefeitura para as instituições de ensino de sua rede levando os alunos e as alunas aos equipamentos culturais, além do mapeamento e da divulgação feitos pela secretaria de educação de atividades culturais para as escolas etc. É importante frisar que a oferta da disciplina de arte na rede por áreas de conhecimento tem reforçado a importância da arte na escola em suas abordagens específicas. Nesse sentido, a presença de um especialista em teatro, ministrando esta aula na instituição, torna a realidade da recepção teatral muito mais presente e necessária.

[...] na história do ensino do teatro a recepção (apreciar e avaliar) não foi elemento de análise; recentemente passou a ser considerada como um dos focos do ensino porque se percebeu que os dois pólos do ensino - produção e recepção, estão associados, não é possível desenvolver um sem o outro. São procedimentos que tornam o educando um observador crítico e facilitam a aquisição de linguagem apropriada. Ampliam-se as possibilidades de que o espectador se abra para a intervenção dos signos na sua percepção, uma vez que, ao reconhecer ou identificar um sistema de ações, o espectador se sente livre para interagir com ele (ROSSETO, 2008, p. 18).

A presença de um professor ou professora especialista na área do teatro, ministrando esta disciplina dentro das escolas, torna-se uma contribuição fundamental para o aperfeiçoamento da área. As propostas pedagógicas baseadas no fazer e no apreciar teatro possibilitam aos educandos experimentar a produção cênica e aprofundar seu repertório de possibilidades do uso da linguagem teatral. Assim, alunos e alunas podem rever suas criações, seus pré-conceitos, suas proposições, dentre outros. Abrir a possibilidade de apreciação teatral para os alunos e as alunas é 
importante também por apresentar outras formas de expressão cênica, que não são as formas de expressão usualmente utilizadas pela mídia, enriquecendo o desenvolvimento da aprendizagem teatral na escola.

Os processos de fazer e apreciar artísticos não ficam restritos ao conhecimento da linguagem da arte, mas perpassam um vasto campo de conhecimentos que atravessam fronteiras de disciplinas escolares. A comunicação artística, tanto no ato de fazer quanto no ato de apreciar, interpõe processos dinâmicos de elaboração, pesquisa, imaginação e sensibilidade. $\mathrm{O}$ artista ou a artista se expõe através do processo e do produto artístico, comunica ao outro no ato da fruição da obra.

Uma das particularidades do conhecimento em Arte está no fato de que, nas produções artísticas, um conjunto de idéias é elaborado de maneira sensível, imaginativa, estética por seus produtores ou artistas. De diversos modos, esse conjunto sensorial-de-idéias aparece no produto de arte enquanto este está sendo feito e depois de pronto ao ser comunicado e apreciado por outras pessoas (PARÂMETROS CURRICULARES NACIONAIS (ENSINO MÉDIO), 2002, p. 48).

O processo de comunicação artística não se restringe a um processo unilateral, no qual o/a artista comunica e o/a apreciador (a) escuta. Diferentemente disso, a atividade artística possui uma fluência de dinâmica de diálogo onde o papel do (a) receptor (a) ultrapassa os limites da fruição unicamente, colocando-o (a) no lugar de produtor (a) juntamente com o/a artista.

O prazer ou o desprazer de estar no circuito da cultura reservado aos espectadores, leitores ou ouvintes, o espaço dos que consomem e receptam, não os exime de serem também produtores. Concomitantemente aos que inventam e constroem os produtos e artefatos, também os receptores os produzem e criam quando os recebem e em tempos e espaços que excedem o momento mesmo da recepção [...] (FERREIRA, 2006, p. 01).

\section{Apresentação do Projeto}

proposta de intervenção prática investigada no contexto da instituição escolar foi planejada através da realização de dois proje1 tos: um de Formação de Público e um de Formação de Espectadores, para duas turmas distintas do ensino médio do Instituto Estadual de Educação. A ideia foi relacionar os dois projetos verificando qual deles surtia maior efetividade para potencializar o estudo da recepção teatral na escola.

O projeto foi desenvolvido através do estudo da área da Pedagogia do Espectador, baseado nos relatos e apontamentos feitos pelo au- 
tor Flávio Desgranges ${ }^{1}$ de uma proposta desenvolvida nas instituições educacionais da Prefeitura Municipal de São Paulo, com intuito de formação de espectadores. A atividade base foi utilizada como referência, sendo feitas as adaptações e implementações necessárias para o desenvolvimento da prática em outro contexto que possui peculiaridades e demandas diferenciadas.

A investigação abrange o campo da recepção teatral com foco restrito na Pedagogia do Espectador. O projeto desenvolvido para implementação na escola está baseado em pesquisar procedimentos pedagógicos que ajudem a despertar o interesse do aluno espectador pela fruição teatral.

A pedagogia do espectador está calcada fundamentalmente em procedimentos adotados para criar o gosto pelo debate estético, para estimular no espectador o desejo de lançar um olhar particular à peça teatral, de empreender uma pesquisa pessoal na interpretação que se faz da obra, despertando seu interesse para uma batalha que se trava nos campos da linguagem. Assim se contribui para formar espectadores que estejam aptos a decifrar os signos propostos, a elaborar um percurso próprio no ato da leitura da encenação, pondo em jogo sua subjetividade, seu ponto de vista, partindo de suas experiências, sua posição, do lugar que ocupa na sociedade. A experiência teatral é única e cada espectador descobrirá sua forma de abordar a obra e de estar disponível para o evento (DESGRANGES, 2003, p. 30).

Através de intervenções práticas desenvolvidas com alunos foi possível analisar formas de potencializar os momentos de fruição teatral, oportunizados com ou na escola, com o intuito de transformar estes momentos em possibilidades reais de aprendizagem da linguagem teatral e de também criar o gosto pela fruição e pelo debate estético desta atividade.

Para tanto, foi necessário diferenciar dois tipos de projetos com a perspectiva de poder verificar, através da análise dos resultados, qual deles apresentaria um resultado mais profícuo para o fim esperado. A proposta foi elaborada com o intuito de comparar duas possibilidades de atividades diferentes desenvolvidas com os alunos e alunas: uma se refere à formação de público teatral e a outra, à formação de espectadores teatrais. Embora em um primeiro momento as duas propostas pareçam iguais, existem entre elas diferenças bastante significativas que possibilitam desenvolver os projetos e compará-los.

O Projeto de Formação de Público tem como objetivo proporcionar aos alunos o acesso físico ao teatro, enquanto o Projeto de Formação

1 O relato da experiência do autor está no livro "Pedagogia do Teatro: Provocação e Dialogismo" e refere-se ao Projeto de Formação de Público, desenvolvido pela Secretaria Municipal de Cultura de São Paulo entre os anos de 2001 e 2004. 
de Espectadores visa proporcionar acesso físico e de aproximação da linguagem teatral com mediações através de procedimentos pedagógicos.

Um projeto de formação de público teatral foca prioritariamente a ampliação do acesso físico, facilitando a ida e aumentando o interesse pela frequentação ao teatro. Um projeto de formação de espectadores, por sua vez, cuida não somente de pôr o espectador diante do espetáculo, mas trata também da intimidade desse encontro, estreitando laços afetivos, afinando a sintonia, mediando a relação dialógica entre o espectador e obra de arte (DESGRANGES, 2011, p. 157).

Proporcionar a frequentação do teatro aos alunos por si só já cumpre um papel importante e fundamental no que diz respeito à democratização da cultura. Possibilitar o acesso aos bens culturais, proporcionar o contato com a linguagem cênica, criar o sentimento de pertencimento aos locais e equipamentos onde são disponibilizados os bens culturais, iniciar um processo de criação de um hábito de usufruto da arte, são contribuições tanto para a área artística e cultural quanto para o exercício da cidadania destes sujeitos. Porém, quando há possibilidade de ir além e mediar esta relação, pode-se obter ganhos na profundidade que esta experiência marca o espectador participante no âmbito social.

(...) criar condições para que eles [crianças e jovens brasileiros] possam ir ver espetáculos talvez seja o primeiro passo a ser dado. Mas (...) possibilitar o acesso ao teatro não significa (...) apenas colocar o espectador infantojuvenil diante de uma peça, mas também fornecer ferramentas para que ele disseque e interprete o evento. Tornar o espectador iniciante mais íntimo da arte teatral e estimulá-lo para um mergulho divertido amplia sua capacidade de aprender o espetáculo e favorece sua socialização, seu acesso ao debate contemporâneo, sua integração e participação sociais (DESGRANGES, 2003, p. 36).

É neste ponto que o Projeto de Formação de Espectadores se diferencia, pois, além de ter que estruturar todas as demandas listadas no projeto anterior, é necessário também focar no duplo acesso: físico e linguístico.

O acesso linguístico da obra, como o próprio termo sugere, opera nos terrenos da linguagem. E trata não apenas da promoção, do estímulo, mas especialmente da constituição do percurso relacional do espectador com a cena teatral, da conquista de sua autonomia crítica e criativa (...) (DESGRANGES, 2008, p. 76).

Além de proporcionar o contato do público com o produto artístico, pretende-se com este tipo de atividade, criar dinâmicas que possam potencializar a experiência da atividade de recepção do espectador. Essas dinâmicas têm como objetivo propor um contato qualitativo de cada espectador com a obra, pois este tipo de projeto "(...) quer trabalhar com as individualidades, com as subjetividades, com as conquistas efetivadas por 
cada espectador no processo em curso" (DESGRANGES, 2008, p. 77).

As dinâmicas são propostas através de procedimentos pedagógicos mediados para estreitar a relação do espectador com a atividade artística.

O despertar do interesse do espectador não pode acontecer sem a implementação de medidas e procedimentos que tornem viáveis seu acesso ao teatro. Na verdade, duplo acesso: físico e linguístico. Ou seja, tanto a possibilidade do indivíduo frequentar espetáculos quanto a sua aptidão para a leitura de obras teatrais (...) (DESGRANGES, 2003, p. 29).

Este tipo de projeto busca uma capacitação do espectador através da implementação de procedimentos que extrapolam o momento da fruição teatral propriamente dita. Estes procedimentos extraespetaculares buscam ascender um diálogo entre o espectador e a obra, proporcionando uma experiência significativa e por isso desejada. Portanto, “(...) formar espectadores não se restringe a apoiar e estimular a frequentação, é preciso capacitar o espectador para um rico e intenso diálogo com a obra, assim, o desejo pela experiência artística" (DESGRANGES, 2003, p. 29).

Flávio Desgranges ao refletir sobre a forma de aquisição do gosto por algo, afirma que o gosto também advém do aprendizado. É preciso conhecer, considerar relevante, ter um grau de intimidade para criar apreço sobre algo. Citando Brecht, o autor aponta que o autor alemão gostaria que os espectadores teatrais fossem especializados como as plateias esportivas, que possuem conhecimento técnico e tático para jogar e apreciar o jogo, sentindo-se aptos a dar palpites e debater sobre o mesmo.

O futebol, considerado uma paixão nacional em nosso contexto brasileiro, apresenta todo um movimento pedagógico durante a vida dos indivíduos que os formam a ser conhecedores desta atividade. Os espectadores são conhecedores de regras, táticas, funções, dentre outros aspectos. Isso acontece tanto pela fruição possibilitada em larga escala pela mídia, como pela atividade de jogar que é mobilizada desde a infância em brincadeiras e também como conteúdo escolar. Refletindo sobre este movimento é possível crer que se o mesmo movimento de aprendizado e especialização fosse feito em relação ao teatro, esta arte poderia suscitar o mesmo interesse que o esporte, pois "ir ao teatro ou gostar de teatro, também se aprende. E ninguém gosta de algo sem conhecê-lo (...)” (DESGRANGES, 2003, p. 33).

O Projeto de Formação de Espectadores então mobiliza a instância de proporcionar ao espectador um contato mais aprofundado com a arte teatral, com vistas a sua especialização para poder participar ativamente do debate estético, despertar o gosto pelo teatro e conquistar autonomia crítica e interpretativa em relação às manifestações teatrais.

O desenho do projeto de desenvolvimento de aprendizagem na escola, que investiguei em decorrência do Mestrado Profartes, teve como foco 
a comparação de um projeto que possibilitou somente o acesso físico ao teatro e outro que utilizou procedimentos pedagógicos antes e depois dos momentos de apreciação teatral pelos alunos espectadores. Os dois projetos relacionados foram feitos com o objeto de reflexão e análise do professor-autor do projeto para futuras intervenções em sua prática educativa.

\section{Os Procedimentos Extraespetaculares}

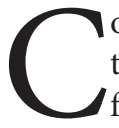

om base no projeto denominado "Formação de Público" da Prefeitura Municipal de São Paulo, descrito por Flavio Desgranges, foi feito o desenho da proposta pedagógica, objeto da pesquisa. Foram utilizados como procedimentos pedagógicos extraespetaculares: os debates entre artistas e espectadores e os ensaios de desmontagem.

No que se refere aos debates entre espectadores e artistas, foram levados em conta os dois objetivos principais explicitados pelo autor: “(...) a revelação dos meandros da arte teatral e o convite a que os espectadores formulassem concepções pessoais da cena" (DESGRANGES, 2006, p. 160). O momento do debate dos espetáculos foi oportunizado para todos os alunos, mesmo aqueles que estariam participando somente do projeto de Formação de Público.

As orientações para o debate foram de que artistas e professor deveriam ser cuidadosos para poder "estimular os participantes do projeto a produzirem interpretações pessoais acerca dos acontecimentos cênicos (...)" (DESGRANGES, 2006, p. 161), não tentar explicar o espetáculo quando submetidos a perguntas com este intuito pelos espectadores, mas devolver as perguntas aos mesmos, estimulado-os a elaborar respostas individuais às provocações feitas a eles pela apresentação da obra cênica.

Os ensaios de desmontagem são entendidos como procedimentos pedagógicos de mediação teatral oferecidos na escola antes e depois dos espetáculos.

(...) alguns focos de investigação seriam selecionados para serem especialmente estudados, dinamizando a recepção dos participantes. A desconstrução da encenação se dava com a proposição aos espectadores de exercícios teatrais semelhantes aos que os artistas realizaram no processo de construção do espetáculo (...) (DESGRANGES, 2006, p. 166).

Anteriormente ao espetáculo é desenvolvido o ensaio de desmontagem de preparação, em que são desenvolvidos procedimentos pedagógicos para aproximar o espectador do evento cênico, sem por isso descrever o que será visto. No momento posterior à fruição artística é proposto o ensaio de desmontagem de prolongamento, no qual os participantes podem expor suas interpretações pessoais sobre o espetáculo de forma cênica. 


\section{O Desenvolvimento da Proposta}

proposta foi organizada para desenvolver o experimento de Forma-
ção de Espectadores (acesso físico e linguístico) para uma turma, e
o experimento de Formação de Público (acesso físico) para outra, ambas do ensino médio de escola pública da região de Florianópolis.

Esta forma de aplicação foi desenhada para análise do seguinte critério: possibilitar que as duas turmas assistissem ao mesmo espetáculo, podendo assim analisar/verificar através dos dados coletados se havia diferença no aprofundamento da experiência estética entre a turma que participou do experimento de Formação de Espectadores e a turma que participou do experimento de Formação de Público.

O cronograma do projeto foi elaborado de forma a contemplar os horários de aulas dos alunos na escola, sendo:

- Uma aula para Aplicação do Questionário Pré-Projeto para as duas turmas

- Uma aula de ensaio de desmontagem de preparação do espetáculo Pequeno Monólogo de Julieta (PR) para a turma do Projeto Formação de Espectadores

- Assistir espetáculo Pequeno Monólogo de Julieta (PR) no horário de aula na escola

- Uma aula de ensaio de desmontagem de prolongamento somente para a turma do Projeto de Formação de Espectadores; e aplicação de questionário de recepção do espetáculo Pequeno Monólogo de Julieta (PR) para as duas turmas

O espetáculo oferecido para fruição das turmas foi o Pequeno Monólogo de Julieta (PR) da Cia Círculo, com texto e direção de Christiano Scheiner e atuação solo da atriz Gilca Rigotti. A ação se inicia no momento anterior ao suicídio da personagem Julieta, do texto Romeu e Julieta de William Shakespeare, quando esta acorda no sepulcro e vê seu amante Romeu morto. O texto amplia o momento de suicídio da personagem que dialoga com um Romeu que não está presente, mas que passa a existir no espaço e nos objetos.

O ensaio de desmontagem para este experimento foi planejado e executado com o desenvolvimento de procedimentos extraespetaculares, com predominância de atividades práticas e teatrais, aproximadas às realizadas para a criação do espetáculo. O ângulo de ataque escolhido para o ensaio de preparação foi o trabalho do ator/atriz e a construção de imagens cênicas, 
sendo que os jogos escolhidos para desenvolver a atividade seguiram este direcionamento de proporcionar aos alunos uma experiência semelhante às que a atriz havia tido na criação da obra.

O ensaio de desmontagem de preparação aconteceu na semana anterior à apresentação do espetáculo e teve duração de 45 minutos, iniciando com jogos teatrais direcionados para a criação de imagens e finalizando com a criação de cenas estimuladas por um trecho do texto Romeu e Julieta de William Shakespeare.

A apresentação aconteceu dentro da sala de dança anexa ao ginásio, nas dependências da instituição escolar, durante horário da aula de cultura dos alunos e sendo disponibilizado apenas para algumas turmas. Esta abordagem foi necessária em função de diversas dificuldades que ocorreram no decorrer do desenvolvimento do projeto para levar os alunos até um equipamento teatral - e que foram relatadas minuciosamente no texto da dissertação -, como o não comparecimento dos alunos para as atividades fora do horário escolar e a negativa da escola em possibilitar a saída dos alunos no momento de aula para a atividade, com a justificativa de que perderiam aulas de outras disciplinas.

O espetáculo foi contratado por mim, que tive de arcar com os custos do mesmo, além de organizar o espaço, equipamento e logística para a realização. A apresentação foi executada no dia 27 de novembro, no horário da aula que ministrei para turma de teatro e que foi o grupo que participou do projeto de Formação de Espectadores. Além desta turma, também estavam presentes mais duas turmas de teatro e uma de dança. Os alunos das outras duas turmas de teatro que não tiveram o desenvolvimento de procedimentos pedagógicos para a recepção do espetáculo foram os participantes do grupo de Formação de Público.

A atriz Gilca Rigotti achou necessário, diante da proposta e do diferencial do espaço de apresentação, fazer uma conversa de introdução ao espetáculo, antes de inicia-lo. Visto que a atriz inicia o trabalho em cena e que não havia recursos de iluminação e o som foi operado de forma visível ao público, este procedimento foi primordial para criar o ambiente de concentração e entendimento da proposta cênica. A atriz usou 10 minutos para esta conversa inicial e fez um resumo do texto Romeu e Julieta. Falou sobre o momento do mesmo texto que deu origem ao espetáculo, discorreu sobre as condições normais de apresentação do espetáculo em um equipamento teatral e sobre o histórico de apresentações e sua trajetória artística e profissional. Finalizou dizendo que ia se concentrar e iniciar o espetáculo, mostrando o momento pré-expressivo do ator antes de entrar em cena.

O espetáculo iniciou com a ambientação sonora e posteriormente a atriz iniciou a interpretação do texto dramático. Os objetos de cena eram o par de botas de Romeu, um colchão e uma adaga. Na parte inicial da 
apresentação tivemos um imprevisto, alguns alunos juntamente com um professor desavisado começaram a jogar bola no ginásio, e o som dos gritos e das batidas da bola no chão ecoaram em todo o ambiente, atrapalhando a plateia de alunos para ouvir o texto dado pela atriz. Logo, as professoras que acompanhavam a atividade conseguiram sanar o problema.

Embora este momento inicial fosse necessário para o entendimento de todo o espetáculo, foi interessante notar que a atitude concentrada dos alunos que estavam assistindo não se desfez. Mesmo com a interferência ocorrida, os alunos continuaram assistindo com muita atenção e notei que todos mantinham os olhos direcionados para a cena, acompanhando a atriz em seus gestos e movimentações.

Ao finalizar o espetáculo iniciamos um debate com todos os alunos, que durou cerca de 10 minutos. O tempo teve de ser regulado, pois os alunos de dança precisavam ensaiar e os de teatro tinham outras demandas. Foram feitas outras perguntas sobre aspectos profissionais da vida de um ator/atriz, de como era fazer um monólogo, o que era necessário para obter um bom resultado de atuação e como era possível se concentrar com o barulho imprevisto que ocorreu. A atriz respondeu a todas as perguntas de forma bastante didática e informal.

Como decorrência de falta de tempo no cronograma, em virtude de diversos imprevistos ocorridos durante o desenvolver da proposta - como a greve do magistério estadual, dentre outras descritas na dissertação -, o ensaio de desmontagem de prolongamento, que seria feito na semana posterior à fruição espetacular, não pôde ser realizado com a turma do experimento de formação de espectadores. A última aula do ano letivo seria a única oportunidade de executar esta atividade, porém, este dia já estava agendado para outras demandas escolares de apresentações finais das produções dos alunos de todas as turmas.

\section{COMParando os EXPERIMENTOS}

Foi possível verificar, através da análise dos questionários de recepção, que os alunos participantes do experimento de Formação de Espectadores apresentaram um nível maior de aproximação com o espetáculo em relação ao grupo do experimento de Formação de Público. Sendo assim, é possível afirmar que, no contexto de desenvolvimento desta pesquisa, o procedimento extraespetacular de ensaio de desmontagem de preparação mostrou-se efetivo, no sentido de estimular o interesse dos alunos pelo teatro, através da aproximação com a linguagem e proporcionando aptidão para participar do debate estético. 
Numa análise quantitativa do retorno obtido dos questionários de recepção em relação ao total de questionários de pré-recepção, verificouse que um número bastante superior de participantes do experimento de Formação de Espectadores completaram a segunda etapa, enquanto no grupo do experimento de Formação de Público o número foi bem abaixo do esperado.

Este indicativo quantitativo de participação dos grupos pode nos levar a supor que a utilização de procedimento extraespetacular de ensaio de desmontagem de preparação estimulou os alunos a preencher o questionário, ou seja, a experiência de aproximação influenciou a vontade de discorrer e expor opiniões sobre o espetáculo, estabelecendo um diálogo com a obra.

Segundo Freire (1977) o diálogo é um fenômeno humano revelado através da palavra, que é constituída por duas dimensões solidárias: ação e reflexão. Quando um dos elementos sacrifica o outro, acontece a palavra inautêntica, ou seja, quando há reflexão sem ação, torna-se palavreria, verbalismo, bla-bla-bla, e quando há ação sem reflexão, torna-se ativismo. $\mathrm{O}$ autor explica que o diálogo é um ato de criação entre os sujeitos, não um ato de depósito de ideias de um sujeito no outro, ou seja, é o "[...] encontro dos homens, mediatizados pelo mundo, para pronunciá-lo[...]", uma exigência existencial, um ato de criação, é transformar o mundo.

Neste sentido, ao verificarmos a quantidade bastante superior de alunos do grupo do experimento de Formação de Espectadores que se sentiram aptos a dialogar com a obra através do questionário de recepção, temos condições de afirmar que o ensaio de desmontagem de preparação proporcionado aos participantes deste grupo estimulou efetivamente um diálogo entre os espectadores e a obra. Estes se sentiram seguros e estimulados a dialogar com o espetáculo através do ato de pronunciar seus depoimentos no preenchimento do questionário.

A análise dos depoimentos relatados nos questionários também trouxe indicativos na mesma direção, sendo possível verificar uma adesão maior de respostas dos alunos do grupo do experimento de Formação de Espectadores em quase todos os blocos de perguntas como os relativos ao Impacto, a Visualização da Proposta, as Atuações, a Direção e a Interpretação.

No que se refere às possíveis influências dos procedimentos extraespetaculares do ensaio de desmontagem de preparação, pôde-se encontrar indicativos destes nas respostas dos alunos do experimento de Formação de Espectadores nos blocos referentes ao Impacto, à Visualização da Proposta, às Atuações, à Direção e à Interpretação.

Foi possível verificar que somente os alunos do experimento de Formação de Espectadores relataram a existência de expectativas em relação 
ao espetáculo assistido e à mudança das mesmas. Observou-se no outro grupo a falta de expectativas anteriores, o que pôde justificar a abstenção de muitos em responderem à questão que versava sobre este tema.

As questões que relacionavam o espetáculo com a experiência pessoal de cada participante não foram respondidas por todos os alunos. De qualquer forma, alguns demonstraram que estas relações haviam acontecido, mas seus relatos demonstravam uma dificuldade de exposição destas experiências no questionário. Estas questões também tiveram maior adesão de respostas do grupo do experimento de Formação de Espectadores.

O retorno obtido com o desenvolvimento da proposta pedagógica possibilita afirmar que, no contexto onde foi desenvolvida a pesquisa, a utilização do procedimento pedagógico do ensaio de desmontagem de preparação mostrou-se efetivo no ensino do teatro na escola. Houve sinalizações significativas no aprofundamento da recepção teatral proporcionada aos alunos do grupo, que foi desenvolvido este experimento principalmente no que concerne à vontade de dialogar com a obra e na ênfase dada aos elementos trabalhados no ensaio para reflexão e análise das questões propostas. 


\section{REFERÊNCIAS}

BRASIL. PCN+ Ensino Médio: orientações educacionais complementares aos parâmetros curriculares nacionais. Brasília: MEC, 2002.

CABRAL, Beatriz Ângela Vieira. Teatro e pressupostos curriculares. In: Subsídios para a Reorganização Didática no Ensino Fundamental. Secretaria Municipal de Educação, Prefeitura Municipal de Florianópolis, 2000. p. 223-232.

DESGRANGES, Flávio. A pedagogia do espectador. São Paulo: Hucitec, 2003. 2006.

. Pedagogia do teatro: provocação e dialogismo. São Paulo: Hucitec,

- Teatralidade tátil: alterações no ato do espectador. Sala Preta: revista de Artes Cênicas. São Paulo: Escola de Comunicação e Artes da Universidade de São Paulo. v.8, 2008, p. 11-19.

. Mediação teatral: anotações sobre o projeto formação de público. Revista Urdimento, Florianópolis: Universidade do Estado de Santa Catarina. n.10, 2008, p. 75-83.

O efeito estético, finalidade sem fim. Revista Urdimento, Florianópolis: Universidade do Estado de Santa Catarina. n.17, 2011, p. 6369.

FERREIRA, Taís. Teatro infantil, crianças espectadoras, escola: um estudo acerca de experiências e mediações em processos de recepção. 2005. Dissertação (Mestrado em Educação) - Universidade Federal do Rio Grande do Sul, Porto Alegre, 2005.

Estudos culturais, recepção e teatro: uma articulação possível? Revista Fênix, v.3, 2006, p. 1-20.

FREIRE, Paulo. Pedagogia do oprimido. Rio de Janeiro: Paz e Terra, 1977. PROJETO JULIETA. Blog do espetáculo Pequeno Monólogo de Julieta do Grupo Círculo de Florianópolis. Santa Catarina. Disponível em: < http://projetojulieta.blogspot.com.br/>. Acesso em: 18 ago. de 2015.

ROSSETO, Robson. Pedagogia do Teatro: um estudo sobre a recepção. 2007. Dissertação (Mestrado em Teatro) - Universidade do Estado de Santa Catarina, Florianópolis, 2007. 